\title{
Consumer Perceived Value of Organic Vegetables: Does Ethnic Group Matter?
}

\author{
Ong Choon Hee* and Tan Koh Lin
}

Azman Hashim International Business School, Universiti Teknologi Malaysia, Johor Bahru, 81310, Malaysia

\begin{abstract}
This study examined the role of ethnic groups on factors influencing the perceived value of organic vegetables among consumers in Malaysia. An online survey questionnaire collected 385 responses. Partial least squares-structural equation modeling (PLS-SEM) was used to assess the validity, reliability, hypothesis testing, importance-performance map analysis (IPMA) of the study constructs. Partial least squares-multi-group analysis (PLS-MGA) was employed to examine whether there are significant differences among various ethnic groups. The findings revealed that food safety concerns, health concerns, and trust in organic food claim significantly influenced the consumer perceived value of organic vegetables. This study offers new findings regarding the role of ethnic groups in explaining significant differences among consumers toward the perceived value of organic vegetables. It also provides essential information to the ministry of agriculture, organic farmers, dealers, and retailers in developing marketing strategies and expansion plans to achieve higher household expenditures on organic vegetables.
\end{abstract}

Keywords: Consumer, ethnic group, food safety, health, organic vegetables, trust, perceived value

ARTICLE INFO

Article history:

Received: 1 September 2020

Accepted: 14 January 2021

Published: 26 March 2021

DOI: https://doi.org/10.47836/pjssh.29.1.21

E-mail addresses:

ongchoonhee@gmail.com (Ong Choon Hee)

imkohlin@gmail.com (Tan Koh Lin)

*Corresponding author

\section{INTRODUCTION}

In Malaysia, although the daily consumption of vegetable per-capita has steadily increased by $70 \%$ from the $1980 \mathrm{~s}(66 \mathrm{~g})$ to the $2000 \mathrm{~s}$ $(112 \mathrm{~g})$, it is still far below the World Health Organization (WHO) recommended dietary guideline of $240 \mathrm{~g}$ (Andrew et al., 2014). Despite most Malaysians expressing a positive perceived value of organic 
vegetables, they do not consume them regularly despite the blooming organic food consumption rate worldwide for the past 20 years (Dettman \& Dimitri, 2010). Marketability issues for Malaysian organic vegetables remain as challenges in light of the efforts to promote the consumption of organic vegetables.

According to Voon et al. (2011), the trust in organic food claims is significantly linked to consume organic food owing to the credence nature of it. Consumers are not able to evaluate effectively because the benefits of organic food cannot be observed directly or immediately. Moreover, growing food safety concern is another issue that often influences consumer perceived value of organic vegetables (Hoefkens et al., 2009). Nevertheless, organic vegetables are usually perceived as healthier than conventional vegetables. It is reasonable to believe that consumers are always willing to use health concerns as a reference when choosing organic vegetables (Chen, 2009). Perceived value is the focus of this research because it is related to consumers' attitudes toward, and social acceptance of, organic vegetables. Several studies quote that food safety concern, health concern, and trust in organic food claims as the key factors determining the success or failure of organic food (Hsu et al., 2016; Leong \& Paim, 2015; Liang, 2016). Realizing the factors mentioned above, we are interested in investigating these factors in a Malaysian context to predict consumer perceived value of organic vegetables. This topic, however, is still limited from the Malaysian consumers' perspectives. Although some studies have investigated consumers' intention to purchase organic food (Hsu et al., 2016; Janssen, 2018; Kasteridis \& Yen, 2012; Niu \& Wohlgenant, 2013; Rana \& Paul, 2017; Shaharudin et al., 2010), the perceived value among consumers from different ethnic groups (i.e., Malay, Chinese, and Indian) in Malaysia has never been explored in this regard. Hence, this study attempts to bridge the gap by examining the role of ethnic groups on factors influencing consumer perceived value of organic vegetables.

\section{LITERATURE REVIEW AND HYPOTHESIS DEVELOPMENT}

\section{Theoretical Foundations}

The theory of consumption values (TCV) is a conceptual model proposed by Sheth et al. (1991) which describes and explains consumer choice. It clarifies that consumer choice is underpinned by various consumption values such as functional value, emotional value, conditional value, social value, and epistemic value (Sheth et al., 1991). Functional value describes that consumers decide to use a product based on how it can fulfil their utilitarian needs. However, emotional value affects a consumer's decision in consuming a product because of a product's capability to arouse emotions while using it. Next, conditional value explains the benefits of the products or services that consumers receive when utilizing them in a specific context. Further, social value influences consumer's decisions in buying or using the products or services owing to their association 
with other groups of consumers and the products' social image. Finally, epistemic value refers to the consumer's interest in experiencing new products or services that can provide novelty and arouse curiosity. According to Sheth et al. (1991), a specific consumer choice may be influenced by one or several consumption values. A past study by Sweeney and Soutar (2001) used functional value and social value to measure consumer perceived value. However, this research adopts the dimensions of functional value, emotional value, and social value of TCV as fundamentals to establish the conceptual framework. Food safety concern was selected to represent functional value whereas trust in organic food claims acts for emotional value. Besides, health concern refers to the social value dimension of the TCV. Also, the ethnic group is chosen as a moderator in this study based on the social identity theory by Tajfel and Turner (1986). Social identity theory is a theory used to explain inter-ethnic group behaviours based on their beliefs, religion, language, culture, and perceived value. Thus, the theory of consumption values is complemented with the social identity theory to better predict consumer perceived value of organic vegetables in this research context. Based on the theoretical foundations above, the conceptual framework is established (see Figure 1).

\section{Perceived Value}

The concept of perceived value refers to the customers' assessment of the merits of a product or service based on what they received and when they used it (Zeithaml,
1988). Perceived value is a unidimensional construct that can be measured by a set of criteria to evaluate a consumer's perception of value toward a product (Agarwal \& Teas, 2002). It influences consumer attitudes and predicts intention (Petrick \& Backman, 2002). Consumer perceived value of organic vegetables is the consumers' evaluation of the benefits they will receive from consuming organic vegetables (Fiandari et al., 2019). According to Dagevos and Ophem (2013), the perceived value contained in food may comprise product, process, location, and emotional values. It is the assessment results made by the consumers pertaining to the benefits they obtained when consuming the food (Sirdeshmukh et al., 2002). Similarly, the means-end theory explains that consumers' perceived value is related to their behavior when individuals consume a product or service to fulfill their desired end states (Gutman, 1982). However, Zeithaml (1988) suggested that the establishment of value perceptions among consumers should include contextual or situational factors. Following Zeithaml's (1988) recommendation, this study introduces an ethnic group as a contextual factor to be tested in the research model. The theory of consumption value developed by Sweeney et al. (1996) was used as a basis to select the factors influencing consumer perceived value of organic vegetables. Dimensions of the consumption values such as functional (food safety concern), social (health concern), and emotional (trust in organic food claims) were selected as the predictor constructs of the perceived value of organic vegetables. 


\section{Food Safety Concern}

In food-related research, the word "safe" is typically regarded as one of the factors driving consumers towards consuming foods. Safe food is a product that consumers can eat without fear of becoming ill (Johar et al., 2020). Vegetable safety is defined as the degree of consumers' worry about pesticide residues, additives, or chemicals added to vegetables that may jeopardize the food quality (Hsu et al., 2016). An organic vegetable is perceived not only as having a high value, but it is also considered as safe food as a result of organic farming practice (Yee \& San, 2011). Food safety concern has received more and more attention in developing countries like Malaysia. Most Malaysian consumers perceive that organic vegetables are less likely to contain harmful substances than conventional vegetables (Michaelidou \& Hassan, 2008). In a review by Shaharudin et al. (2010), food safety is related to the perceived value of organic food. It affects the functional and emotional dimensions of the perceived value when consumers make their choices toward organic food (Curvelo et al., 2019). Further, food safety is a function of belief that gives consumers a positive perception when evaluating the benefits of organic food. Hsu et al. (2016) found that consumers paid more attention to food safety when it came to the use of chemical additives and pesticides in the processing of vegetables. Those manufacturers that provide complete food safety information to the consumers will undoubtedly increase their perceived values of organic vegetables (Hsu et al., 2019). Thus, consumers who are concerned about food safety perceived greater benefits of organic vegetables rather than conventional vegetables. Previous researchers, such as Hsu et al. (2016, 2019), have consistently found a positive link between food safety concerns and the consumer perceived value of organic vegetables. Based on the above explanation, it is hypothesized that:

H1: Food safety concern positively influences consumer perceived value of organic vegetables.

\section{Health Concern}

The health concern is defined as the awareness to link the consumption of nutrients with the results related to health (Sapp, 1997). Consuming organic vegetables is recognized as one of the most critical factors in preventing the development of chronic diseases (Ferrao et al., 2018). In recent times, consumers pay more attention to the health benefits of organic food to achieve a healthy diet. Health concern has a strong effect on consumer perceived value of organic vegetables when it comes to particular circumstances where consumers are having an illness, pregnancy, and other diseases (Richter, 2005). Consumers believe that organically grown vegetables provide substantial health benefits than conventional cultivation (Chen, 2009). According to Sia et al. (2013), organic vegetables have higher nutritional values and contain more significant benefits in preventing illness. Similarly, Ferrao et al. (2018) concurred that those consumers who desired a healthy diet and health-oriented lifestyle commonly perceived organic vegetables as having 
higher contents of nutrients. They are extremely aware of the nutritional issues when selecting vegetables. Nutrient contents are the primary element for a health concern that results in consumers having a positive perceived value of organic vegetables. According to Al Mamun et al. (2020), the young Malaysian population is increasingly interested in having a healthy diet and getting involved in organic food consumption. Therefore, it is hypothesized that:

H2: Health concern positively influences consumer perceived value of organic vegetables.

\section{Trust in Organic Food Claims}

Trust in organic food claims is understood as belief, expectation, and feeling that consumers have about the product due to its credence nature (Voon et al., 2011). Credence good is a product that is difficult for the consumers to value after purchase or even after consumption. Consequently, consumers may rely on product information, labeling, brands, advertisements, certifications, and the reputation of the retailers. If they believe the retailer is highly committed to human health and environmental concerns, their trust in the retailer will increase. When trust is applied to organic vegetables, indicators like labels and certification logos tagged on the products will contribute to the establishment of trust (Liang, 2016). Further, organic certification assures vegetables are grown without using chemicals and pesticides (Barrett et al., 2002). Popular organic certification and labeling will create more trust in consumer perception (Nguyen et al., 2020). Baker and Ozaki (2008) mentioned that consumers generally trusted popular brands of organic food because the risk was much lower than unpopular ones. Lin (2009) also agreed that consumers might lose their trust and refused to purchase organic products if the producers were accused of polluting the environment. When consumers are in a situation where there exists insufficient relevant information, trust in organic food claims could reduce perceived risk for all the parties involved (Voon et al., 2011). Moreover, observable attributes of organic food serve as measures of trustworthiness and build positive perceived value (Sa'ari $\&$ Koe, 2014). In a nutshell, the greater the trust in organic food claims, the higher the sense of the perceived value of organic products (Atkinson \& Rosenthal, 2014). Hence, it is hypothesized that:

H3: Trust in organic food claims positively influences consumer perceived value of organic vegetables.

\section{Ethnic Group}

An ethnic group is operationally defined as a group of people who have similar beliefs, religion, language, culture, values, and behaviors within a nation. An ethnic group is also referred to as race in the population of this study. The way consumers perceived organic food depends on various demographic factors such as gender, age, level of income, education, and presence of children in the household (Omar et al., 2016; Vega-Zamora et al., 2020). Although research investigating the 
demand for vegetables among households is common (Kasteridis \& Yen, 2012; Niu \& Wohlgenant, 2013), very few have studied the role of an ethnic group in perceiving the values of organic vegetables. In Malaysia, there are three major ethnic groups in the country; namely, Malay, Chinese, and Indian. The perceived value of organic vegetables may vary among the major ethnic groups. According to Andrew et al. (2014), other ethnic groups spend more on fresh vegetables and preserved vegetables than Malays. However, the study did not indicate the perceptions of the ethnic groups as regards organic vegetables. Different ethnic groups may have a dissimilar overall perceived value of organic vegetables owing to their beliefs and culture. Therefore, it is hypothesized that:
H4a: The influence of food safety concern on consumer perceived value of organic vegetables varies across different ethnic groups.

$\mathrm{H} 4 \mathrm{~b}$ : The influence of health concern on consumer perceived value of organic vegetables varies across different ethnic groups.

H4c: The influence of trust on organic food claims on consumer perceived value of organic vegetables varies across different ethnic groups.

\section{Conceptual Framework}

The above literature review and hypothesis development establish the following conceptual framework (see Figure 1) that guides this study.

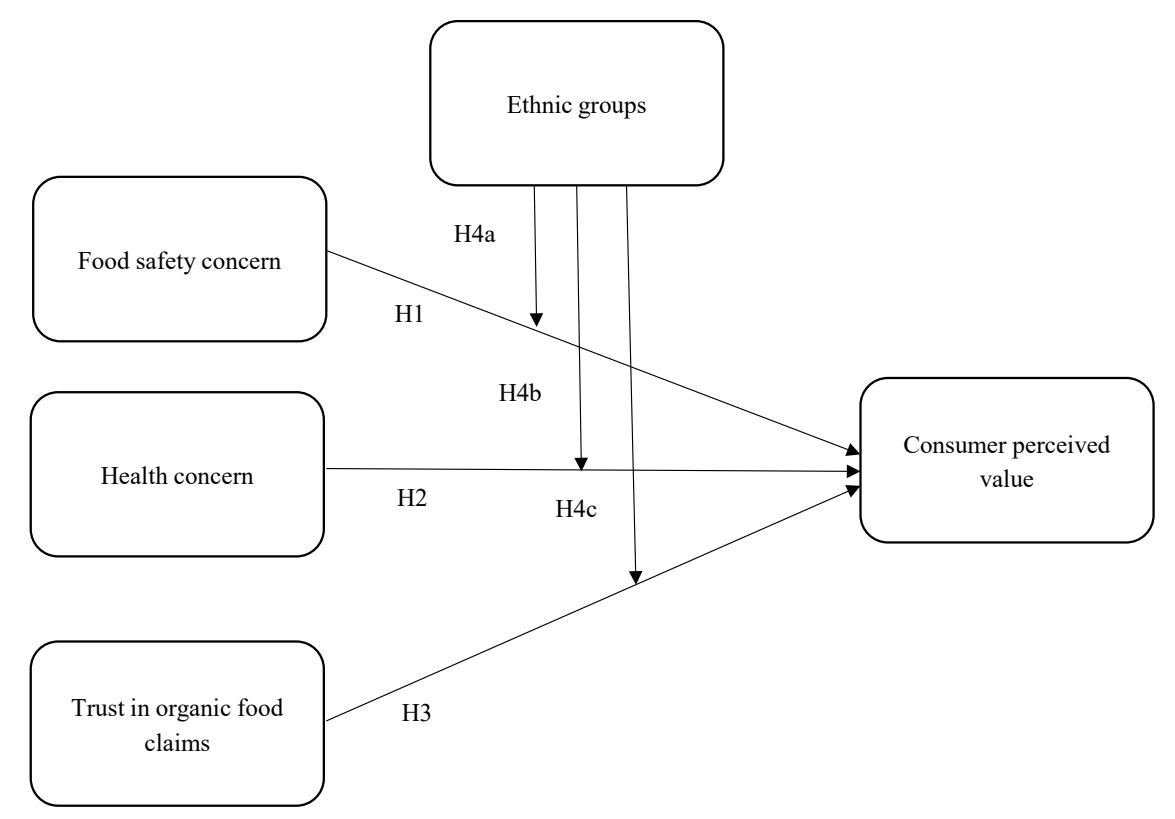

Figure 1. Conceptual framework 


\section{METHOD}

\section{Population and Sampling Method}

The target population of this study comprised consumers who live in Malaysia. According to the Department of Statistics Malaysia (2019), approximately 32.58 million people live in Malaysia. According to Cohen (1992), the minimum required sample size for a research model of three arrows pointing at a construct is 59 . The number of samples is associated with a significance level of $5 \%, 80 \%$ of statistical power, and a minimum $\mathrm{R}^{2}$ value of .25 . In the present study, the researcher used the judgmental sampling method to obtain the samples from the city of Johor Bahru, Malaysia. Judgmental sampling is purposive sampling where it allows researchers to approach their target population of interest directly. In this research, the researchers select the respondents where they fit the criteria of consumers or potential consumers of organic vegetables. The reason for selecting respondents who live in Johor Bahru is because it is a major city in the southern region of Malaysia and it is the most urbanized city in the country (Department of Statistics Malaysia, 2019).

\section{Measures}

Measures for the study constructs were adapted and modified from previous studies with strong reliability coefficients. Details of the steps are presented in Appendix 1. A 5-point Likert scale was utilized accordingly for all the measures.

\section{Data Collection Procedure}

This cross-sectional research used an online survey questionnaire to collect data from the respondents. Online survey forms were sent to the respondents, who were Johor Bahru residents, via emails and social media networks. A total of 385 responses were collected and prepared for subsequent data analysis.

\section{Data Analysis}

Partial least squares-structural equation modeling (PLS-SEM) was used to assess the validity, reliability, hypothesis testing, importance-performance map analysis (IPMA) of the study constructs. Partial least squares-multi-group analysis (PLS-MGA) was employed to examine whether there are significant differences among various ethnic groups.

\section{RESULTS}

\section{Profile of the Respondents}

Table 1 shows the profile of the respondents. There were 173 male respondents and 212 female respondents. The majority of the respondents had a Bachelor's degree $(60.8 \%)$, followed by a Diploma/Certificate (16.4\%), Master's (12.7\%), high school certificate $(9.6 \%)$, and Doctoral degree $(0.5 \%)$. In terms of ethnic group, $35.6 \%$ of the respondents were Malays, $47.8 \%$ of the respondents were Chinese, and the rest of the respondents were Indians (16.6\%). Most of the respondents were between 25 and 54 years $(83.6 \%)$. 
Table 1

Profile of the respondents

\begin{tabular}{lcc}
\hline Description $(\mathrm{n}=385)$ & Frequency & Percentage \\
\hline Gender & 173 & 44.9 \\
Male & 212 & 55.1 \\
Female & & \\
Age & 29 & 7.5 \\
Below 24 & 322 & 83.6 \\
$25-54$ & 27 & 7 \\
$55-64$ & 7 & 1.8 \\
Above 64 & & \\
Education & 37 & 9.6 \\
High School & 63 & 16.4 \\
Diploma/ Certificate & 234 & 60.8 \\
Bachelor's Degree & 49 & 12.7 \\
Master's Degree & 2 & 0.5 \\
Doctoral Degree & & \\
Ethnic group & 137 & 35.6 \\
Malay & 184 & 47.8 \\
Chinese & 64 & 16.6 \\
Indian & &
\end{tabular}

\section{Measurement Model Assessment}

This study employs the two-step approach to assess the measurement and structural models. First, we examined the measurement model by assessing indicator reliability, composite reliability, convergent and discriminant validity. The values for Cronbach's Alpha and composite reliability of all the constructs were above the recommended value of .7; thus, they were considered reliable. Next, convergent validity was evaluated by examining the outer loadings and values of the average variance extracted (AVE). Those indicators with outer loadings lesser than .7 were removed from the list of indicators. Two of the indicators (HC3, FSC1) were discarded during the analysis. Subsequently, other outer loadings for all the constructs were found to exceed .7 and the values of AVEs were above .5 , indicating the establishment of convergent validity (Hair Jr. et al., 2017). Results of the measurement model are shown in Table 2.

Next, to assess the discriminant validity of the constructs, loading, and crossloadings with Fornell-Larcker criterion were used in the analysis (Hair Jr. et al., 
2017). The loadings for all the study constructs were well above all of its loadings on other constructs, thus showing evidence of discriminant validity (Fornell \& Larcker, 1981) (see Table 3). Likewise, all the diagonal values (square root of AVEs) were found greater than the off-diagonal values in Table 4. Therefore, discriminant validity was established.

Table 2

Results of the measurement model

\begin{tabular}{|c|c|c|c|c|c|}
\hline Constructs & Indicators & Loadings & $\begin{array}{c}\text { Cronbach's } \\
\text { Alpha }\end{array}$ & $\begin{array}{l}\text { Composite } \\
\text { Reliability }\end{array}$ & AVE \\
\hline \multirow[t]{5}{*}{$\mathrm{CPV}$} & CPV1 & 0.881 & .930 & 0.947 & 0.781 \\
\hline & CPV2 & 0.861 & & & \\
\hline & CPV3 & 0.885 & & & \\
\hline & CPV4 & 0.903 & & & \\
\hline & CPV5 & 0.848 & & & \\
\hline \multirow[t]{4}{*}{$\mathrm{HC}$} & $\mathrm{HC} 1$ & 0.871 & .904 & 0.932 & 0.774 \\
\hline & $\mathrm{HC} 2$ & 0.889 & & & \\
\hline & $\mathrm{HC} 4$ & 0.886 & & & \\
\hline & $\mathrm{HC} 5$ & 0.872 & & & \\
\hline \multirow[t]{5}{*}{ FSC } & FSC2 & 0.704 & .849 & 0.891 & 0.621 \\
\hline & FSC3 & 0.771 & & & \\
\hline & FSC4 & 0.777 & & & \\
\hline & FSC5 & 0.817 & & & \\
\hline & FSC6 & 0.862 & & & \\
\hline \multirow[t]{4}{*}{$\mathrm{T}$} & $\mathrm{T} 1$ & 0.854 & .922 & 0.945 & 0.811 \\
\hline & $\mathrm{T} 2$ & 0.905 & & & \\
\hline & $\mathrm{T} 3$ & 0.921 & & & \\
\hline & $\mathrm{T} 4$ & 0.920 & & & \\
\hline
\end{tabular}

Notes: CPV: Consumer perceived value; HC: Health concern; FSC: Food safety concern; T: Trust in organic food claims. 
Table 3

Loading and cross-loadings

\begin{tabular}{lcccc}
\hline Indicators & CPV & HC & FSC & T \\
\hline CPV1 & $\mathbf{0 . 8 8 9}$ & 0.326 & 0.356 & 0.322 \\
CPV2 & $\mathbf{0 . 8 9 1}$ & 0.285 & 0.422 & 0.400 \\
CPV3 & $\mathbf{0 . 8 7 9}$ & 0.427 & 0.431 & 0.408 \\
CPV4 & $\mathbf{0 . 8 4 2}$ & 0.374 & 0.387 & 0.323 \\
CPV5 & $\mathbf{0 . 9 1 5}$ & 0.381 & 0.438 & 0.335 \\
HC1 & 0.440 & $\mathbf{0 . 8 7 1}$ & 0.413 & 0.370 \\
HC2 & 0.327 & $\mathbf{0 . 8 8 9}$ & 0.447 & 0.343 \\
HC4 & 0.327 & $\mathbf{0 . 8 8 6}$ & 0.423 & 0.319 \\
HC5 & 0.314 & $\mathbf{0 . 8 7 2}$ & 0.377 & 0.344 \\
FSC2 & 0.346 & $\mathbf{0 . 7 0 4}$ & 0.150 \\
FSC3 & 0.275 & 0.366 & $\mathbf{0 . 7 7 1}$ & 0.092 \\
FSC4 & 0.422 & 0.334 & $\mathbf{0 . 7 7 7}$ & 0.118 \\
FSC5 & 0.254 & 0.335 & $\mathbf{0 . 8 1 7}$ & 0.209 \\
FSC6 & 0.353 & 0.455 & $\mathbf{0 . 8 6 2}$ & 0.238 \\
T1 & 0.447 & 0.342 & 0.209 & $\mathbf{0 . 8 5 4}$ \\
T2 & 0.325 & 0.448 & 0.309 & $\mathbf{0 . 9 0 5}$ \\
T3 & 0.391 & 0.332 & 0.118 & $\mathbf{0 . 9 2 1}$ \\
T4 & 0.354 & 0.294 & 0.113 & $\mathbf{0 . 9 2 0}$ \\
\hline
\end{tabular}

Notes: CPV: Consumer perceived value; HC: Health concern; FSC: Food safety concern; T: Trust in organic food claims.

Table 4

Discriminant validity - Fornell-Larker criterion

\begin{tabular}{lcccc}
\hline Constructs & CPV & DHC & FSC & T \\
\hline CPV & $\mathbf{0 . 8 8 4}$ & & & \\
HC & 0.409 & $\mathbf{0 . 8 8 0}$ & & \\
FSC & 0.462 & 0.472 & $\mathbf{0 . 7 8 8}$ & \\
T & 0.407 & 0.394 & 0.209 & $\mathbf{0 . 9 0 0}$ \\
\hline
\end{tabular}

Notes: CPV: Consumer perceived value; HC: Health concern; FSC: Food safety concern; T: Trust in organic food claims.

\section{Descriptive Analysis}

Mean and standard deviation was used to analyze the response level of respondents. A five-point Likert scale was employed to measure the level of agreement among the respondents. If the score is less than 2.33 , it is categorized as low. If the score is within the range of 2.33 to 3.66 , it is classified 
as moderate whereas if it is above 3.66, it is considered high. Table 5 shows that food safety concern has the highest mean value $(M=4.272)$ among the constructs. It denotes that the respondents were having high levels of food safety awareness concerning organic vegetables. Next, the respondents' perceived value of organic vegetables was high $(\mathrm{M}=3.909)$ as well, indicating that their understanding of the benefits of consuming organic vegetables is high. However, both constructs of health concern $(\mathrm{M}=3.075)$ and trust in organic food claims (3.392) were reported to have moderate levels as shown in Table 5.

Table 5

Descriptive statistics

\begin{tabular}{llllll}
\hline Constructs & $\mathrm{N}$ & Min & Max & Mean & $\begin{array}{l}\text { Standard } \\
\text { Deviation }\end{array}$ \\
\hline CPV & 385 & 1.00 & 5.00 & 3.909 & 0.799 \\
HC & 385 & 1.00 & 5.00 & 3.075 & 0.925 \\
FSC & 385 & 2.20 & 5.00 & 4.272 & 0.613 \\
T & 385 & 1.00 & 5.00 & 3.392 & 0.861 \\
\hline
\end{tabular}

Notes: CPV: Consumer perceived value; HC: Health concern; FSC: Food safety concern; T: Trust in organic food claims.

\section{Collinearity Assessment}

Collinearity assessment is crucial to ensure that the path coefficients are not biased before structural model assessment. Following the variance inflation factor (VIF) guidelines, it is acceptable if the VIF values for the predictor constructs are lower than 5 , and the tolerance values stay above 0.2. Table 6 indicates that all VIF values of the predictor constructs were below 5 , and the tolerance levels were above 0.2 . Thus, the results provide evidence of non-collinearity.

Table 6

Collinearity assessment

\begin{tabular}{llll}
\hline Predictor Constructs & Tolerance & VIF & Target Construct \\
\hline HC & 0.686 & 1.458 & CPV \\
FSC & 0.776 & 1.288 & \\
$\mathrm{~T}$ & 0.845 & 1.184 & \\
\hline
\end{tabular}

Notes: VIF: Variance inflation factor; CPV: Consumer perceived value; HC: Health concern; FSC: Food safety concern; T: Trust in organic food claims. 


\section{Structural Model Assessment}

The research model was tested with 385 cases with subsamples of 5000 to estimate the significance of path coefficients by using a bootstrapping procedure (Preacher $\&$ Hayes, 2008). According to the analysis results, the predictor constructs can explain $32.8 \%\left(\mathrm{R}^{2}=.328\right)$ of the total variance in consumer perceived value, which is below moderate in this case (Hair Jr. et al., 2017). Nevertheless, the predictive relevance of the model is above zero $\left(\mathrm{Q}^{2}=.239\right)$, indicating that the research model has the predictive ability (Hair Jr. et al., 2017). The hypothesis testing results show that all the path coefficients are significant at the level of $1 \%$ (see Table 7 ), thus supporting $\mathrm{H} 1$, $\mathrm{H} 2$, and $\mathrm{H} 3$.

Table 7

Structural model assessment and hypothesis testing

\begin{tabular}{lccccc}
\hline Hypothesis & Path & $\beta$ & STDEV & $t$-statistics & Decision \\
\hline H1 & FSC $\rightarrow$ CPV & $.339^{* * *}$ & 0.049 & 6.865 & Supported \\
H2 & HC $\rightarrow$ CPV & $.137 * * *$ & 0.052 & 2.615 & Supported \\
H3 & T $\rightarrow$ CPV & $.283 * * *$ & 0.047 & 6.042 & Supported \\
\hline
\end{tabular}

Notes: ***t-value: 2.58 (1\%); STDEV: Standard Deviation; CPV: Consumer perceived value; HC: Health concern; FSC: Food safety concern; T: Trust in organic food claims.

\section{Partial Least Squares-Multiple Group Analysis (PLS-MGA)}

This research applies PLS-MGA to examine the moderating role of an ethnic group in the research model. According to the guidelines provided by Henseler et al. (2009), if the $p$-value of the path coefficients is smaller than .05 or greater than .95 , it indicates that there is a significant difference between the groups. Table 8 shows the path coefficients $(\mathrm{HC} \rightarrow \mathrm{CPV})$ for Indian vs. Malay and Indian vs. Chinese are significant at the $5 \%$ error level, where the $p$-value is smaller than .05 . Hence, the results revealed that the Indian community is significantly higher than Malay and Chinese in perceiving organic vegetables in the aspect of diet-health concern; thus, H4b is accepted. However, the results for other paths ( $\mathrm{FSC} \rightarrow \mathrm{CPV}$ ) and $(\mathrm{T} \rightarrow \mathrm{CPV})$ did not indicate any significant difference among the ethnic groups. Therefore, H4a and H4c are not accepted.

\section{Importance-Performance Map Analysis (IPMA)}

The IPMA results help decision-makers prioritize areas for managerial actions. Figure 2 schematically displays the IPMA results with consumer perceived value as the target construct. Food safety concern has the highest importance level at 0.434 and it is treated as the most critical construct for managerial actions. 
Table 8

Partial Least Squares-Multi-Group Analysis (PLS-MGA) results for the ethnic groups

\begin{tabular}{lccc}
\hline Path & $\begin{array}{c}\text { Ethnic Group } \\
\text { (G1 vs G2) }\end{array}$ & $\begin{array}{c}\text { Ethnic Group } \\
(\mathrm{G} 3 \text { vs G1) }\end{array}$ & $\begin{array}{c}\text { Ethnic Group } \\
(\mathrm{G} 3 \text { vs G2) }\end{array}$ \\
\hline FSC $\rightarrow$ CPV & 0.712 & 0.835 & 0.940 \\
$\mathrm{HC} \rightarrow$ CPV & 0.522 & $\mathbf{0 . 0 2 7}^{*}$ & $\mathbf{0 . 0 2 6 *}$ \\
$\mathrm{T} \rightarrow$ CPV & 0.653 & 0.107 & 0.156 \\
\hline
\end{tabular}

Notes: G1 (Malay), G2 (Chinese), G3 (Indian). *significant differences between groups at 5\% error level $(p<.05$ or $p>.95)$, CPV: Consumer perceived value; HC: Health concern; FSC: Food safety concern; T: Trust in organic food claims.

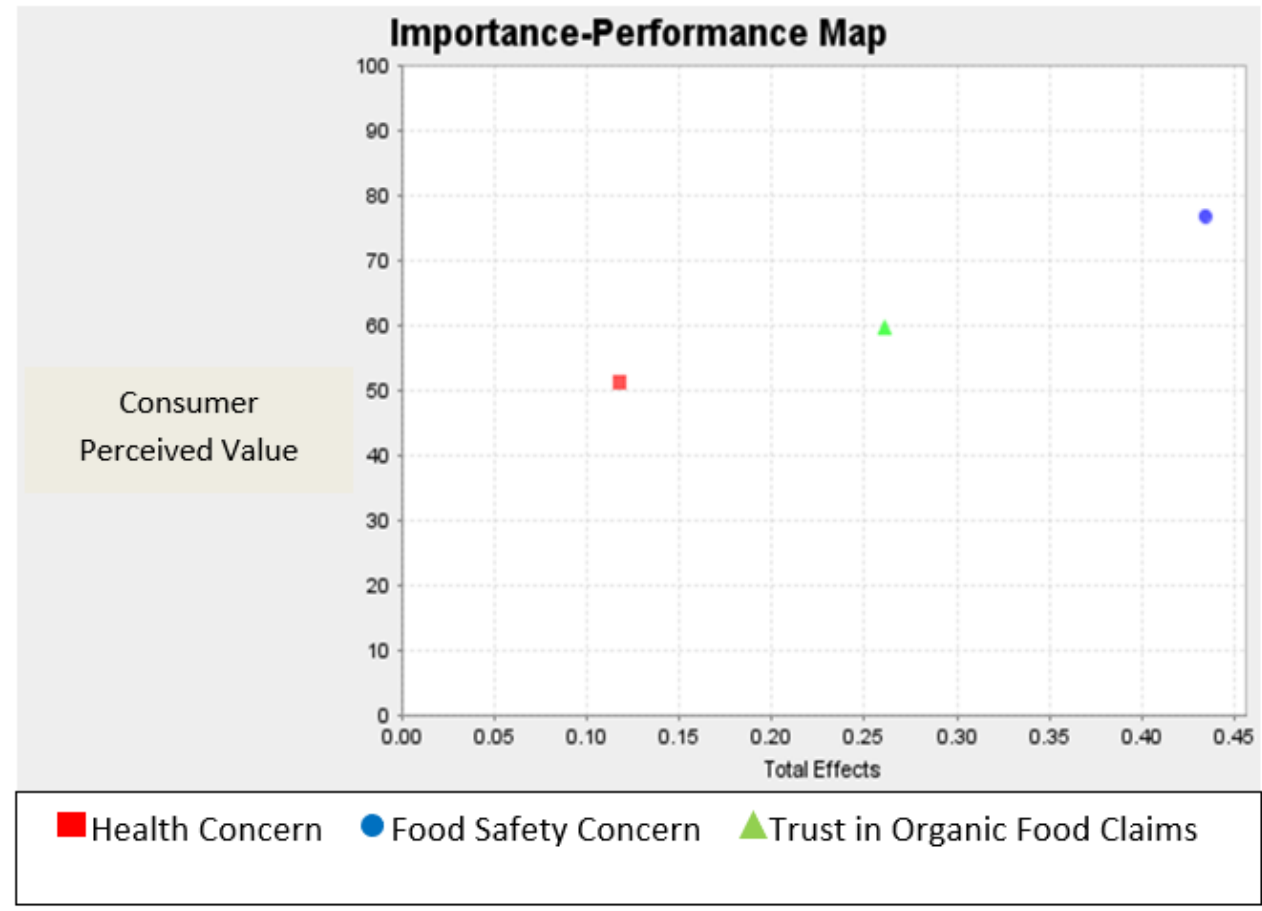

Figure 2. Importance-performance map analysis (IPMA) results with consumer perceived value (CPV) as the target construct

\section{DISCUSSION}

Referring to the statistical results of the study, all predictor constructs significantly influenced the consumer perceived value of organic vegetables. These results further validate $\mathrm{H} 1, \mathrm{H} 2$, and $\mathrm{H} 3$. The path of $\mathrm{FSC} \rightarrow \mathrm{CPV}(\beta=.339, p<.01)$ specifies the significant positive influence of food 
safety concern on consumer perceived value. This finding is in line with the study of Chandran et al. (2016) where the researchers mentioned that food safety concern had the most significant influence on the consumer perceived value of organic food. In Malaysia, consumers thought organic vegetables are safer to consume because they are chemical-free compared to conventional vegetables. However, for vegetables to be certified organic, the process of production must conform to the Malaysian Standard MS 1529: 2015 titled "Plant-based organically produced foods-requirements for production, processing, handling, labeling, and marketing." (Department of Standards Malaysia, 2015). This certification standard provides confidence and trust in food safety where the production and processing of organic vegetables must not use any mineral fertilizers, pesticides, and pollutants (Hsu et al., 2016). Further, Lian and Yoong (2019) were of the same opinion that food safety information such as the organic certification logo played a crucial role in assuring consumers of food safety.

Next, the second hypothesis testing result revealed that health concern $(\beta=.137$, $p<.01)$ significantly influences the consumer perceived value of organic vegetables. The rationale behind this finding is that health concern has become a salient determining factor for consuming organic food (Chen, 2009). The increasing growth of health concerns in Malaysia has increased the demand for organic vegetables. This is evident when Malaysia has recorded the highest obesity and overweight rate among
Asian countries, with male and female having these abnormalities constituted $64 \%$ and $65 \%$ of the population (WHO, 2019). Obesity may result in major illnesses, such as heart disease, hypertension, and diabetes. Additionally, the increasing affluence of the population has also provided consumers with more alternatives in consuming healthier food such as organic vegetables (Ling et al., 2018). This finding is in line with the past studies of Legrand and Sloan (2006), Lohr (2011), and Nasution et al. (2011) where they mentioned health needs were factors that motivated consumers to perceive the positive value of organic food.

Further, the third hypothesis testing result showed that trust in organic food claims $(\beta=.283, p<.01)$ significantly influences the perceived value of organic vegetables. Although researchers claimed that food safety and health concerns are central to the existing consumer perceived values (Chen, 2009; Miller \& Cassady, 2012), signaling theory explains that consumers would choose to trust a product if signals exist externally on the product. In the case of organic vegetables, the certification label, place of origin, and reputable brands served as signals (Roe \& Sheldon, 2007). Similarly, Baker and Ozaki (2008), Essoussi and Zahaf (2009), and Lin (2009) asserted that consumer trust in organic food was built on the certification process, popular brands, and reputation of producers. However, confidence in organic vegetables is difficult to ascertain. This is due to the absence of visible characteristics that can differentiate organic vegetables 
from non-organic vegetables. Without proper labeling and tagging on the organic products, it may lead the consumers to have a similar perception toward organic and non-organic vegetables as they are alike in appearance.

When investigating significant differences among the ethnic groups, the effect of a specific ethnic group on the likelihood of consuming organic vegetables yields different results. The Indian community was found to be significantly concerned as regards health than Malay and Chinese (see Table 8). This result explains that although Indian merely constitutes around $7 \%$ of the total population in Malaysia, they are more likely to perceive positive values of organic vegetables owing to health concern perception. As mentioned by Mohd-Any et al. (2014), culture is the key element that shapes people's beliefs, values, and eating habits of different ethnic groups in Malaysia. Culture may be a possible factor behind vegetable consumption because of dietary principles in the Indian community. Generally, Indians refrain from eating beef and adopt strict vegetarian diets in their daily meals.

\section{CONCLUSION}

This research has successfully examined the role of ethnic groups on consumer perceived value of organic vegetables in Malaysia. It highlights the significant differences among various ethnic groups on the relationship between the determining factors and the perceived value of organic vegetables. Practically, this study pinpoints food safety concern as the prominent construct for managerial actions. It suggests that focusing on the significant ethnic group and food safety concern should be able to increase consumer perceived value of organic vegetables.

\section{THEORETICAL IMPLICATIONS}

This study attempts to examine the role of ethnic groups (i.e., Malay, Chinese, and Indian) in understanding different patterns of the perceived value of organic vegetables among the three major ethnic groups in Malaysia. The PLS-MGA results revealed that the Indian community had a higher level of health concern than the Malay and Chinese, which in turn affected their perceived value of organic vegetables. These results correspond to a study by Andrew et al. (2014) where they explained when nutritional education was progressing, public perceptions on healthy lifestyles were also on the rise. The factor of health concern accepts the fact that being healthy needs the blend of food contents and nutrition (Mohd-Any et al., 2014). Hence, this study extends the theory of consumption value by introducing a contextual factor of an ethnic group in the research framework to better understand the perceived value of organic vegetables among different ethnic consumers in a multiracial country.

\section{MANAGERIAL AND POLICY IMPLICATIONS}

According to the findings of IPMA, food safety concern has the highest importance level at 0.434. Managerial actions should 
emphasize food safety concerns in this aspect. The agricultural ministry of Malaysia should prioritize food safety practices and promote food safety assurance for organic vegetables by ensuring the certification process is strictly following the certification standard. Regular training should enhance knowledge of food safety among the producers. Other related parties (i.e., training providers, certification consultants) that are involved in the process of organic certification must be accredited by the Malaysian department of agriculture. The Malaysian organic logo (myOrganic) must be made known to the consumers via nationwide campaigns, social media networks, newspapers, and television to build greater food safety awareness on organic food (Hsu et al., 2016). Further, strict enforcement of legislation related to organic food production should be in place to develop consumer trust and positive perceived values of organic vegetables (Lian \& Yoong, 2019). The department of agriculture, organic farmers, dealers, and retailers are required to understand the effects of food safety concerns if they were to gain more positive perceived values from the consumers.

Besides, producers of organic vegetables could use the findings of this research to strategize their business plan. For example, a company should emphasize food safety when promoting the benefits of organic vegetables via all possible advertising channels. Moreover, the findings of this study also reveal the significant role of the ethnic group, which affects consumer perceived value of organic vegetables.
Therefore, in the aspect of marketing implications, market penetration strategies should focus on offering consumers in-depth information regarding the benefits of organic vegetables according to the specific ethnic groups' concerns and perceived values. In this regard, organic vegetable producers can divide their target market into specific cohorts based on ethnic groups. This will allow their businesses to precisely approach a group of consumers with specific needs and wants. In the long run, this strategy benefits the companies because they can allocate their resources effectively to gain a competitive advantage. Although economic research suggests that Asian households are less likely to buy organic vegetables (Dettmann \& Dimitri, 2010), however, with this effort, will eventually result in greater expenditures on organic vegetables among Asians and Malaysians in particular.

\section{LIMITATIONS AND FUTURE RESEARCH}

This study has some limitations that need to be addressed. First, this study selected only a major city to conduct data collection. The results obtained may not generalize to the entire population. Future research is proposed to include larger cities in the country and increase the sample size and number of responses collected. Second, the predictor constructs used in this study are not comprehensive; it is suggested that future research should include more relevant predictors, such as price and quality to increase the predictive ability of the research model. Third, we only selected three major 
ethnic groups in Malaysia for this research. Future studies may consider including other ethnic minorities in the country to produce a more comprehensive report of the study.

\section{ACKNOWLEDGEMENTS}

The authors wish to thank the Malaysian Ministry of Higher Education and Universiti Teknologi Malaysia (GUP Tier 2: 15J99) for providing financial support to publish this paper.

\section{REFERENCES}

Agarwal, S., \& Teas, R. K. (2002). Crossnational applicability of a perceived quality model. Journal of Product and Brand Management, 11(4-5), 213-236. https://doi. org/10.1108/10610420210435425

Al Mamun, A., Hayat, N., \& Zainol, N. R. (2020). Healthy eating determinants: A study among Malaysian young adults. Foods 2020, 9(974), 1-18. https://doi:10.3390/foods 9080974

Andrew, K. G. T., Steven, T. Y., Hasan, A. R., \& Muhamad, K. (2014). Household expenditures on vegetables in Malaysia. Journal of Agricultural and Applied Economics, 46(4), 615-634. https:// doi.org/10.1017/s1074070800029138

Atkinson, L., \& Rosenthal, S. (2014). Signaling the green sell: The influence of eco-label source, argument specificity, and product involvement on consumer trust. Journal of Advertising, 43(1), 33-45. https://doi.org/10.1080/00913367.2013 .834803

Baker, J. P., \& Ozaki, R. (2008). Pro-environmental products: Marketing influence on consumer purchase decision. Journal of Consumer Marketing, 25(5), 281-293. https://doi. org/10.1108/07363760810890516
Barrett, H. R., Browne, A. W., Harris, P. J. C., \& Cadoret, K. (2002). Organic certification and the UK market: Organic imports from developing countries. Food Policy, 27(4), 301-318. https:// doi.org/10.1016/s0306-9192(02)00036-2

Chandran, S., Razali, Z., \& Santhirasegaram, V. (2016). A review on organic food production in Malaysia. Horticulturae, 2(3), 1-5. https://doi. org/10.3390/horticulturae2030012

Chen, M. F. (2009). Attitude toward organic foods among Taiwanese as related to health consciousness, environmental attitudes, and the mediating effects of a healthy lifestyle. British Food Journal, 111(2), 165-178. https://doi. org/10.1108/00070700910931986

Cohen, J. (1992). A power primer. Psychological Bulletin, 112(1), 155-159. https://doi. org/10.1037/0033-2909.112.1.155

Curvelo, I., Watanabe, E., \& Alfinito, S. (2019). Purchase intention of organic food under the influence of attributes, consumer trust and perceived value. Revista de Gestão, 26(3), 198211. https://doi.org/10.1108/rege-01-2018-0010

Dagevos, H., \& Ophem, V.J. (2013). Food consumption value: Developing a consumer-centred concept of value in the field of food. British Food Journal, 115(10), 1473-1486. https://doi.org/10.1108/ bfj-06-2011-0166

Department of Standards Malaysia. (2015). Plantbased organically produced foods-requirements for production, processing, handling, labelling and marketing (First revision). http://www.doa. gov.my/index.php/pages/view/377

Department of Statistics Malaysia. (2019). Malaysia (a) a glance. https://www.dosm.gov.my/v1/index. php?r=column/cone\&menu_id=dDM2enNvM0 9oTGtQemZPVzRTWENmZz09

Dettmann, R. L., \& Dimitri, C. (2010). Who's buying organic vegetables? Demographic characteristics of US consumers. Journal of Food 
Products Marketing, 16(1), 79-91. https://doi. org/10.1080/10454440903415709

Essoussi, L. H., \& Zahaf, M. (2009). Exploring the decision-making process of Canadian organic food consumers motivations and trust issues. Qualitative Market Research: An International Journal, 12(4), 443-459. https:// doi.org/10.1108/13522750910993347

Ferrao, A. C., Guine, R. P. F., Correia, P., Ferreira, M., Cardoso, A. P., Duarte, J., \& Lima, J. (2018). Perceptions towards a healthy diet among a sample of university people in Portugal. Nutrition \& Food Science, 48(4), 669-688. https://doi.org/10.1108/nfs-10-2017-0205

Fiandari, Y. R., Surachman, S., Rohman, F., \& Hussein, A. S. (2019). Perceived value dimension in repetitive fish consumption in Indonesia by using an extended theory of planned behavior. British Food Journal, 121(6), 1220-1235. https:// doi.org/10.1108/bfj-07-2018-0429

Fornell, C., \& Larcker, D. F. (1981). Structural equation models with unobservable variables and measurement error: Algebra and statistics. Journal of Marketing Research, 18(3), 382-388. https://doi.org/10.1177/002224378101800313

Gutman, J. (1982). A means-end chain model based on consumer categorization processes. Journal of Marketing, 46(2), 60-72. https://doi. org/10.1177/002224298204600207

Ha, N. M., \& Dung, N. T. (2017). To study consumers' use of information on food labels in Vietnam. International Review of Management and Marketing, 7(1), 175-182.

Hair Jr., J. F., Hult, G. T. M., Ringle, C., \& Sarstedt, M. (2017). A primer on partial least squares structural equation modelling (PLS-SEM). Sage Publications.

Henseler, J., Ringle, C. M., \& Sinkovics, R. R. (2009). The use of partial least squares path modeling in international marketing. In $\mathrm{R}$.
R. Sinkovics \& P. N. Ghauri (Eds.), New challenges to international marketing (Advances in international marketing, Vol. 20). Emerald Group Publishing Limited. https://https://doi. org/10.1108/S1474-7979(2009)0000020014

Hoefkens, C., Verbeke, W., Aertsens, J., Mondelaers, K., \& Van Camp, J. (2009). The nutritional and toxicological value of organic vegetables: Consumer perception versus scientific evidence. British Food Journal, 111(10), 1062-1077. https://doi.org/10.1108/00070700920992916

Hsu, S. Y., Chang, C. C., \& Lin, T. T. (2016). An analysis of purchase intentions toward organic food on health consciousness and food safety with/under structural equation modeling. British Food Journal, 118(1), 200-216. https://doi. org/10.1108/bfj-11-2014-0376

Hsu, S. Y., Chang, C. C., \& Lin, T. T. (2019). Triple bottom line model and food safety in organic food and conventional food in affecting perceived value and purchase intentions. British Food Journal, 121(2), 333-346. https://doi. org/10.1108/bfj-07-2017-0403

Janssen, M. (2018). Determinants of organic food purchases: Evidence from household panel data. Food Quality and Preference, 68(1), 19-28. https://doi.org/10.1016/j.foodqual.2018.02.002

Johar, M. G. M., Yajid, M. S. A., \& Shukri, S. M. (2020). Influence of nutrient rich and ecofriendly organic food products on the purchase intentions of Malaysian consumers. Systematic Reviews in Pharmacy, 11(1), 791-798.

Kasteridis, P., \& Yen, S. T. (2012). U.S. demand for organic and conventional vegetables: A bayesian censored system approach. Australian Journal of Agricultural and Resource Economics, 56(3), 405-425. https://doi.org/10.1111/j.14678489.2012.00589.x

Legrand, W., \& Sloam, P. (2006). Customers“ preferences to healthy meals. In J. S. Chen (Ed.), Advances in hospitality and leisure (Vol. 
2). Emerald Group Publishing Limited. https:// doi.org/10.1016/S1745-3542(05)02014-X.

Leong, T. P., \& Paim, L. (2015). Mediating effects of intention on the factors affecting organic food products consumption among Chinese Generation-Y in Malaysia. International Journal of Business Research and Management, 6(1), 1-19.

Lian, S. B., \& Yoong, L. C. (2019). Assessing the young consumers' motives and purchase behavior for organic food: An empirical evidence from a developing nation. International Journal of Academic Research in Business \& Social Sciences, 9(1), 69-87. https://doi.org/10.6007/ ijarbss/v9-i1/5364

Liang, R. D. (2016). Predicting intentions to purchase organic food: The moderating effects of organic food prices. British Food Journal, 118(1), 183199. https://doi.org/10.1108/bfj-06-2015-0215

Lin, S. H. (2009). Exploratory evaluation of potential and current consumers of organic cotton in Hawaii. Asia Pacific Journal of Marketing and Logistics, 21(4), 489-506. https://doi. org/10.1108/13555850910997553

Ling, T. P., Dominic, F. L., \& Shanmugam, A. (2018). The purchase intention of organic foods among working adults in Penang, Malaysia. IOSR Journal of Business and Management, 20(3), 48-59.

Lohr, L. (2011). Factors affecting international demand and trade in organic food products. Changing Structure of Global Food Consumption and Trade, 67-79.

Michaelidou, N., \& Hassan, L. M. (2008). The role of health consciousness, food safety concern and ethical identity on attitudes and intentions towards organic food. International Journal of Consumers Studies, 32(2), 163-170. https://doi. org/10.1111/j.1470-6431.2007.00619.x
Miller, L. M. S., \& Cassady, D. L. (2012). Making healthy food choices using nutrition facts panels: The roles of knowledge, motivation, dietary modifications goals, and age. Appetite, 59(1), 129-139. https://doi.org/10.1016/j. appet.2012.04.009

Mohd-Any, A. A., Mahdzan, N. S., \& Cher, C. S. (2014). Food choice motives of different ethnics and the foodies segment in Kuala Lumpur. British Food Journal, 116(12), 1879-1896. https://doi.org/10.1108/bfj-07-2013-0170

Nasution, R. A., Tarigan., M. M., \& Dhewanto, W. (2011). Consumer attitude and intention to buy organic food as a result of brand extension: An experimental approach. World Journal of Management, 3(1), 75-85.

Niu, L., \& Wohlgenant, M. (2013). Subsidizing fruits and vegetables by income group: A two-stage budgeting approach [Paper presentation]. Agricultural \& Applied Economics Association's AAEA \& CAES Joint Annual Meeting, Washington, USA.

Nguyen, C., Nguyen, Y., \& Quy, T. (2020). Organic foods: What are the driving factors of purchase intention? International Journal of Innovation, Creativity and Change, 13(11), 400-418.

Omar, N. A., Nazri, M. A., Osman, L. H., \& Ahmad, M. S. (2016). The effect of demographic factors on consumer intention to purchase organic products in the Klang Valley: An empirical study. Geografia Online Malaysian Journal of Society and Space, 12(2), 68-82.

Petrick, J. F., \& Backman, S. J. (2002). An examination of the construct of perceived value for the prediction of golf travelers' intentions to revisit. Journal of Travel Research, 41(1), 38-45. https:// doi.org/10.1177/0047287502041001005

Preacher, K. J., \& Hayes, A. F. (2008). Asymptotic and resampling strategies for assessing and 
comparing indirect effects in multiple mediator models. Behavioral Research Methods, 40(3), 879-891. https://doi.org/10.3758/brm.40.3.879

Rana, J., \& Paul, J. (2017). Consumer behavior and purchase intention for organic food: A review and research agenda. Journal of Retailing and Consumer Services, 38, 157-165. https://doi. org/10.1016/j.jretconser.2017.06.004

Richter, T. (2005, November 28-29). Approaches for organic products-implication of recent consumer study results [Paper presentation]. Proceeding of the 1st scientific FQH conference, Frick, Switzerland.

Roe, B., \& Sheldon, I. M. (2007). Credence labeling: Efficiency and distributional implications of several policy approaches. American Journal of Agricultural Economics, 89(4), 1020-1033. https://doi.org/10.1111/j.14678276.2007.01024.x

Sa'ari, J. R., \& Koe, W. L. (2014, August 12-15). The intention to consume organic food among millennial generation [Paper presentation]. Knowledge Management International Conference (KMICe), Malaysia.

Sapp, S. G. (1997). Reliability and validity of nutrition knowledge and diet-health awareness tests developed from the 1989-1991 diet and health knowledge surveys. Journal of Nutrition Education and Behavior, 29(2), 63-72. https:// doi.org/10.1016/s0022-3182(97)70157-2

Shaharudin, M. R., Pani, J. J., Mansor, S. W., \& Elias, S. J. (2010). Factors affecting purchase intention of organic food in Malaysia's Kedah state. CrossCultural Communication, 6(2), 105-116.

Sheth, J., Newman, B., Gross, B. (1991), Why we buy what we buy: A theory of consumption values. Journal of Business Research, 22(2), 159-170. https://doi.org/10.1016/0148-2963(91)90050-8

Sia, B. K., Ooi, B. C., Chong, S. C, Lim, C. S., \& Low, L. T. (2013). Determinants of willingness to pay of organic products. Middle-East Journal of Scientific Research, 14(9), 1171-1179.

Sirdeshmukh, D., Singh, J., \& Sabol, B. (2002). Consumer trust, value, and loyalty in relational exchanges. Journal of Marketing, 66(1), 15-37. https://doi.org/10.1509/jmkg.66.1.15.18449

Sweeney, J. C., Soutar, G. N., Whiteley, A., \& Johnson, L. W. (1996). Generating consumption value items: A parallel interviewing process approach. Asia Pacific Advances in Consumer Research, 2, 108-115.

Sweeney, J., \& Soutar, G. (2001), Consumer perceived value: The development of a multiple item scale. Journal of Retailing, 77(2), 203-220. https://doi. org/10.1016/s0022-4359(01)00041-0

Tajfel, H., \& Turner, J. (1986). The social identity theory of intergroup behavior. In S. Worchel \& W. Austin (Eds.), Psychology of intergroup relations. Nelson-Hall.

Vega-Zamora, M., Parras-Rosa, M., \& TorresRuiz, F. J. (2020). You are what you eat: The relationship between values and organic food consumption. Sustainability 2020, 12(9), 3900. https://doi:10.3390/su12093900

Voon, J. P., Kwang, S. N., \& Agrawal, A. (2011). Determinants of willingness to purchase organic food: An exploratory study using structural equation modeling. International Food and Agribusiness Management Review, 14(2), 103120.

World Health Organization. (2019). Malaysia and WHO call for more investment in primary health care the 21 st century. https://www.who. int/malaysia/news/detail/08-04-2019-malaysiaand-who-call-for-more-investment-in-primaryhealth-care-the-21st-century

Yee, C. J., \& San, N. C. (2011). Consumers' perceived quality, perceived value and perceived risk towards purchase decision on automobile. American Journal of Economics and Business 
Administration, 3(1), 47-57. https://doi. org/10.3844/ajebasp.2011.47.57

Zeithaml, V. A. (1988). Consumer perception of price, quality and value: A means-end model and synthesis of evidence. Journal of Marketing, 52(3), 2-22. https://doi. org/10.1177/002224298805200302 


\section{APPENDIX}

\section{Appendix 1}

\section{Measures for the constructs}

\begin{tabular}{|c|c|c|}
\hline Construct & Measures & Source \\
\hline $\begin{array}{l}\text { Consumer } \\
\text { perceived } \\
\text { value }(\mathrm{CPV})\end{array}$ & $\begin{array}{l}\text { 1. Organic vegetables have more freshness. } \\
\text { 2. Organic vegetables have superior quality. } \\
\text { 3. Organic vegetables are natural food products. } \\
\text { 4. Organic vegetables are tastier. } \\
\text { 5. Organic vegetables have more nutritional } \\
\text { value than conventional vegetables. }\end{array}$ & $\begin{array}{l}\text { Shaharudin et al. } \\
(2010)\end{array}$ \\
\hline $\begin{array}{l}\text { Food safety } \\
\text { concern (FSC) }\end{array}$ & $\begin{array}{l}\text { 1. I'm really worried about food safety because } \\
\text { of my concerns with pesticides and fertilizers. } \\
\text { 2. Food safety of vegetables nowadays concern } \\
\text { me. } \\
\text { 3. I have the impression that organic vegetables } \\
\text { are natural food. } \\
\text { 4. I think organic vegetables are safer to eat. } \\
\text { 5. I take food safety into account a lot in my life. } \\
\text { 6. I am prepared to eat organic vegetables as } \\
\text { they are not harmful. }\end{array}$ & $\begin{array}{l}\text { Shaharudin et al. } \\
\text { (2010) }\end{array}$ \\
\hline $\begin{array}{l}\text { Health concern } \\
\text { (HC) }\end{array}$ & $\begin{array}{l}\text { 1. I take organic vegetables because I'm } \\
\text { concerning about my health. } \\
\text { 2. I take organic vegetables to avoid } \\
\text { compositions that are harmful to my health. } \\
\text { 3. I take organic vegetables because I'm allergic. } \\
\text { 4. I take organic vegetables because I'm afraid } \\
\text { that the food condition of unknown origin } \\
\text { affects my health. } \\
\text { 5. Taking organic vegetables is the way I } \\
\text { recognize higher nutrient contents for my } \\
\text { health. }\end{array}$ & $\begin{array}{l}\text { Ha and Dung } \\
\text { (2017) }\end{array}$ \\
\hline $\begin{array}{l}\text { Trust in } \\
\text { organic food } \\
\text { claims (T) }\end{array}$ & $\begin{array}{l}\text { 1. I trust that those selling organic food are } \\
\text { honest about the organic nature of their } \\
\text { products. } \\
\text { 2. I trust that local producers of organic } \\
\text { vegetables are practicing organic farming. } \\
\text { 3. I trust the organic certification logo on organic } \\
\text { food labels. } \\
\text { 4. I trust the information on organic food labels. }\end{array}$ & Voon et al. (2011) \\
\hline
\end{tabular}

